\title{
From the Unusual to the Useful: Digital Platforms and Co-Working Spaces as Instruments for Human Resource Management in Emerging Economic and Organizational Environments
}

\author{
Leonardo Pompa ${ }^{1}$ \\ ${ }^{1}$ University of Ferrara, Department of Economics and Management, Ferrara, Italy \\ Correspondence: Leonardo Pompa, Department of Economic and Management, via Voltapaletto 7, 44121 Ferrara, \\ Italy. Tel: 39-053-245-5006. E-mail: leonardo.pompa@unife.it
}

Received: June 5, 2017

Accepted: July 10, 2017

Online Published: July 18, 2017

doi:10.5539/ijbm.v12n8p143

URL: https://doi.org/10.5539/ijbm.v12n8p143

\begin{abstract}
In this present economic situation, the use of freelance workers, whose role in organizations runs side by side with that of full time workers, is becoming increasingly more important. The joint presence of these two very different forms of human resource, represents an important challenge to Human Resource Management, which has to adequately exploit the qualities of those who work within the organization, irrespective of the type of contractual ties they may have. Managerial literature has come up with limited contributions on this topic and without finding effective solutions to the integrated management of such an assortment of human resources. In this paper we contribute to fill this literature gap by proposing a conceptual model concerning how using digital platforms and co-working spaces may facilitate the company's human resource management. This particular model outlines how these two instruments can assist the work of HR managers, especially with the conception and implementation of recruitment and motivational processes.
\end{abstract}

Keywords: co-working spaces, digital platforms, gig economy, organizational change, hr management

\section{Introduction}

In this present economic situation, the idea that the labor market is undergoing profound transformation, is becoming increasingly more accepted. According to the Bureau of Labor Statistics, more than 53 million Americans earn income from untraditional forms of labor. This is a stunning number of people if you consider that we are talking about 1 in 3 American workers. You frequently hear people talk about the growth of the so-called "freelancer economy" (Schrader, 2015), which is a form of economy in which full time and steady employment both lose their central role in favour of contractors (Storey et al., 2005), who operate autonomously and without stable work ties to any particular company. The number of temporary works is set to increase over the next few years, with this trend not only involving lowly qualified workers, but also concerning fields with a high concentration of professional workers (Miller \& Miller, 2012).

The presence of freelancers is seen as an essential condition for acquiring specialised skills and for improving innovative processes within an organization (Burke \& Cowling, 2015). Some researchers talk of "micro-work" or "click-work" (Webster, 2016) for highlighting the role Internet has in this recent tendency, which is rewriting the rules of engagement in this current economic context. The fact that there are so many freelance workers should not, however, mean that their role lessens that of full-time workers. In an interesting article, for example, Barley and Kunda (2006) quote the words of a renowned business strategist, Charles Handy, who asserts that flexibility is the key to survival in a global economy and that this flexibility can only be achieved by using freelance workers within the business. Handy's idea is that these workers should be used alongside full-time employees so as, in the event of problems arising, the company can continue to rely on its own employees and easily freeing itself of contractors. Even with differing dynamics, the situation that is occurring on the labor market and, subsequently, within organizations themselves, is an authentic process of the co-presence of employees and independent workers. In such a similar situation, the role of Human Resource Management becomes crucial, and it has to able to show that is able to manage, in an integrated manner, both types of workers, in order to avoid losing the synergy of its employees to that of the contactors, and vice versa. Starting with a review of the most important economic and managerial literature on this topic, we can start to identify those factors, in the presence of which organizations can nowadays more easily come into contact with and manage 
this increasingly wide ranging field of Human Resources. There are at least two elements that appear to assist HRM policies and that help make these policies more effective, especially with regards to recruitment and motivation. These are digital platforms and co-working spaces. Both elements are unique features of this emerging economic context, referred to by many as the "gig-economy" (Zumbrun, 2016). Despite the fact that this issue is common knowledge, academic literature appears to pay little attention to the matter. The aim of this article is to create a starting point for future contributions by those researchers who decide to concentrate on this very current theme, by supplying support to new managerial practices aimed at the management of an ever increasing range of human resources. The aim of this article is also that of conveying the idea that the proper use of digital platforms and co-working spaces can lead to the strategic use of Human Resources which, in an economy ever increasingly based on knowledge, represent the true source of distinction and success of a company.

\section{Gig Economy and Forms of Freelance Workers}

While there is still no clear and unequivocal definition of the "gig economy", we can still trace the most important features of this particular aspect of the economic scene, within which the traditional forms of labor seem to have less importance than before. We can consider the "gigers" as being those who earn their livelihood with an occupation that has no job continuity or stability. All of the transactions relative to this form of employment are usually applied to the fields of digitalized professions. And it is thanks to digital technology that engagement between those who look for freelance workers and freelance workers themselves, can take place. And while these are two extremely different elements, we can often confuse the "gig economy" with the "sharing economy". Even though the two concepts can partially be overlapped, there is no full connection between the two in terms of objectives and relational dynamics. The gig economy, on the other hand, is mainly based on employment deriving from online platforms. According to some, this new economic context will lead to a slow but inevitable decline in full time employment, traditionally linked to fixed hours and salaries. With this in mind, the contractor's work is definitely less secure, and this can only have a negative impact in terms of motivation for those who have the role of a freelancer within companies who take them on.

According to Sara Horowitz, the founder of Freelancers Union, "Freelancing is the new normal" and the "Freelancing in America: 2016" report (Note 1), a yearly independent research commissioned by Freelancers Union and Upwork, both seem to confirm this notion. The voice of these workers will increasingly be heard at a political level. And as the report states, it appears that two out of three independent workers are inclined to vote for candidates who support the interests of freelancers, whose weight at an economical level is already considerable. Data obtained (Freelancing in America Report, 2016) suggests that freelancers earned approximately a trillion dollars during 2015. Some people become freelancers out of need, while many others do so by choice, a choice dictated by the desire to receive higher recognition as a worker, and by having the opportunity to decide on their working hours with greater flexibility. One of the reasons that the number of freelancers continues to rise can be found in the fact that it is an occupation which guarantees a great deal of flexibility. If, on the one hand, independent workers can more easily manage their daily routines, they can also find additional work, alongside that of their main occupation. In this way, a freelancer has considerably more opportunities to earn a double income compared to a regular employee.

Obviously, the explanation of this enormous growth in this form of employment, is technology. Many freelancers can easily offer their services thanks to the wide range of innovative digital instruments, which are ever increasingly connected to small and large worldwide networks of companies and workers, and which can be accessed by any type of electronic device.

The fact, however, that this sector is undergoing continuous expansion, must not lead us to presume that the field of freelancing is without its problems. Once again, according to the "Freelancing in America" report, independent workers worry about a number of problems that concern their profession. The main concern regards the uncertainty surrounding their income and the worry of not receiving adequate payment for their services. Secondly, there is the question of medical insurance. Not having full-time employment means that often they find it difficult to obtain insurance policies that can guarantee the highest level of coverage for the workers and their families.

The expression "freelancer" does itself contain a multitude of meanings and which, as we will see in the following paragraphs, can be interpreted in various ways. Etymologically speaking, the term derives from medieval jargon for describing "freelance" mercenary warriors whose services were not exclusively offered to any single master. Nowadays, freelancers are people who negotiate on their own behalf with an employer who is interested in specific professional aspects that only a freelancer can offer. 
Seeing as the term "freelancer" is, in itself, far too generic, let's try to shed some light on some of the meanings that are usually associated with it. The "Freelancing in America" report sets out 5 different categories of this type of worker:
1) Independent contractors
2) Diversified workers
3) Moonlighters
4) Freelance Business Owner
5) Temporary workers

In the following paragraphs we'll discover the characteristics of each of these categories and learn how their presence plays an important role in the freelance economy.

\subsection{Independent Contractors}

This is the largest category of freelancers. They are workers who do not have one single employer and who carry out their profession in complete autonomy. Their services are temporary and are linked, on an ad-hoc basis, to specific projects. The amount of freedom with which independent contractors carry out their profession means that they can manage their work and spare time with wide margins of autonomy. This is the complete opposite to full-time employees who have little freedom in balancing these two aspects.

If contractors, therefore, have the option of operating in complete autonomy, this is, above all, due to ICT technology which, more or less, allows people to work anywhere in the world and at anytime (Sayah, 2013). Issues of the utmost relevance have, in the past, been raised about the figure of the independent contractor. As Reilly mentions (2015), this category of freelancer should be correctly classified, as very often their role within an organization is very similar that of an employee, and that it can become difficult to distinguish between the two.

An emblematic case was that of Microsoft which, in the eighties, employed a large number of contractors who became so fully integrated into its workforce that in the end it found itself forced to acknowledge their status as employees, therefore having to pay all relative taxes to this new and effectively permanent workforce. The problem of misclassification is one that is extremely prominent in countries like the United States, where companies often hire workers as independent contractors, so as to deprive these workers of certain benefits and avoid the expenses of higher salary conditions. According to some researchers, the wide use of contractors within an organization can be explained by the latter's desire to reduce operating costs while maintaining a high level of flexibility while, at the same time, opening its doors to newer skills (Lemmon et al., 2016). The use of contractors can lead to cost reductions on many fronts. One of these concerns the cost of personnel training. Contractors, in fact, bring to the organization their own means, their own skills and experience, reducing high training costs incurred by employers, which they would otherwise be forced to meet for their employees.

\subsection{Diversified Workers}

This is a category of workers who build their income by having different occupations. In one particular week, for example, a person could work as a secretary, as a tour guide, and as a proof writer. Literature on the subject does not specifically deal with this category of freelancer, even though in the United States alone, there are around 15.2 million diversified workers. At a first glance, it would appear that this category of worker contributes very little to the growth of a company. This is not the case however. Let's take, for example, a company experiencing a staggering rate of growth, such as Uber. In this case, the task of transporting people, the core business activity of the Californian colossal, is assigned to diversified workers. Independent workers usually find it hard to maintain themselves by solely working as a Uber driver and it is for this reason that the definition diversified worker is particularly adapt to the context of this type of business. The Uber example helps us to highlight the fact that in the context of the gig economy, not all freelancers are the same. And it's for this reason that not all of them contribute to the growth of the business in the same way and to the same extent. We should then consider that a diversified worker possesses skills that can be used in various and often very far ranging fields. Here we find another difference between diversified workers and the independent contractors that we mentioned earlier. The latter carry out a more specific line of work and operate with greater incisiveness in the organizational framework in which they work.

\subsection{Moonlighters}

Moonlighters are professionals who, most of the time, have a generally stable occupation, outside of which they have a secondary occupation from which they earn additional income, on top of the income earned from their main occupation. The classical example of a moonlighter is that of a teacher who, in the mornings works at a 
school and then offers private lessons from home in the afternoons. Contrary to the diversified worker, moonlighters have a full-time occupation and prefer to dedicate their skills to activities similar to their principle field of work, and while the diversified worker carries out very different forms of work, the moonlighter will generally remain in the same professional sphere. The moonlighter is an abnormal category of freelancer. This type of worker does, in fact, already have a full-time occupation and could, therefore, avoid the burden of having a second job. Some say that by virtue of this indisputable evidence, some moonlighters have a second occupation as they are strongly attracted to the idea of being able to avoid paying taxes and therefore earn an income which is completely free of all forms of duties (Oliver, 1993).

In this respect, moonlighting is considered to be related to so-called unreported employment, in other words, types of employment that the State is unaware of. Various studies have dealt with this "invisible" labor market (Meriküll \& Staehr, 2010), underlining how difficult it is to supply precise data on this trend, especially if we consider that workers involved prefer to remain anonymous (Schneider F. \& Enste D.H., 2000). As a result, the "shadow economy" is a very difficult argument to deal with, especially due the causes that go towards creating it With regards to this, a number of methods have been put forward to suggest how to carry out exhaustive research on this topic (Dell'Anno, 2016). Turning our focus back to this article, we can, without doubt, assert that the presence of moonlighters within modern organizations should be carefully monitored in order to comprehend the extent to which the current global productive structure depends on the undeclared workforce and, as a result, the level of influence it has on the shadow economy.

\subsection{Freelance Business Owner}

This is a person who is half way between being an independent contractor and a business owner. The freelance business owner is, in fact, he or she who employs one or more employees for offering a particular service. This would be the case of a communications expert who appoints him or herself as the head of a team of people in order to set up an agency. In that way, the services offered by the freelancer are enhanced by the presence of other workers. The freelance business owner can appear to be a professional hybrid figure which is difficult to place in any determined category. In essence, however, this is a freelancer who employs other freelancers for conducting a freelance business. Unlike a business owner, the freelance business owner takes on fewer risks and doesn't concentrate on the same line of business for long periods, as he or she is mainly concentrated on single projects.

Furthermore, the freelance business owner runs a business enterprise in which he is personally involved, and this is a further difference between freelance business owners and a traditional business owner who, in truth, never employs him or herself. In order to work as a freelancer in an economically sustainable manner, and for guaranteeing acceptable standards of efficiency and effectiveness to his business, some people suggest that the freelancer should think like a business owner (Goodman, 2010). In this way, an entrepreneurial approach would help the freelancer to control with extreme care a series of indicators that can reveal the progress of his or her business, such as the hours dedicated to each project, administrative costs and financial requirements. From this point of view, the freelance business owner appears to be the most adapt person to apply this kind of approach. The relationship between freelance enterprises and businesses is at the centre of a debate involving academic research. According to some, freelancing should be recognized as a form of business enterprise (Kitching \& Smallbone, 2012) as this approach would lead to clear advantages in conceptualizing and interpreting the phenomena in a statistically more accurate manner.

\subsection{Temporary Workers}

This is a category of freelance worker that has a single employer or, in any case, a single project to which they are dedicated. Their occupational status is temporary in the sense that, unlike an independent contractor, their services are not used over a continuous period of time but for short and specific periods, with gaps and interruptions, meaning that there are moments in which the worker is completely inactive. This is an example of companies that hire seasonal personnel. The business of these companies can increase, for example, during summertime or Christmas holidays, in periods of the year, therefore, when the number of employees is insufficient for meeting demand for products and / or services, which substantially increases during these periods. A large number of employers find that resorting to temporary workers is an advantage, as most of these workers have already been through a preliminary selection process with specific agencies which test the real merits of the workers' expertise and the potential contribution they can supply to the business in which they will be placed.

This category of worker represents a considerable proportion of freelancers, so much so that between 1998 and 2008 the number of so-called TAW (Temporary Agency Workers) doubled (CIETT, 2010). According to some, these agencies supply a valuable service to organizations as they help to provide greater flexibility to the labor 
market, at lower labor costs, with less responsibility for HR managers and lower expenses for organizations in terms of recruitment and salaries (Torka, 2004).

With regards to temporary workers, there are significant psychological aspects which should be considered. One of the most important is definitely that of commitment, which is particularly difficult to strengthen as workers hired for a short period of time will unlikely feel the desire to be committed with any particular enthusiasm and intensity to the business they will be working for. Some branches of research, however, show that good training techniques for temporary workers can generate surprising and positive results in terms of commitment (De Cuyper \& De Witte, 2008;).

\section{The Impact of Digital Platforms at an Economic-Organizational Level and New Techniques Used by Human Resource Management in Recruitment Processes}

The presence of digital instruments in the world of labor, which help to connect the supply and demand of labor, have become increasingly prominent over the past years. The new agents, on top of the traditional agencies, are those digital platforms where people that are looking for employment can engage with organizations and assess their requirements. Digital platforms are completely transforming the labor market and the means by which organizations focus on hiring new staff. The "Connecting talent with opportunity in the digital age" (2015) report by McKinsey clearly illustrates the impact digitalization has had on a global scale. Experts claim that by 2015 digital platforms will add $\$ 2700$ billion to the global GDP. This is a significant amount and it demonstrates how finding new employment becomes quicker and more effective. Thanks to these new digital platforms, for example, anyone can take up professions that best suit their skills and experience. In countries with particularly high unemployment rates, being able to create a more dynamic labor market is an undeniable advantage. Organizations that use these instruments do not only use them for placing new personnel into their organization, but for improving the motivational aspect of their workers as well. According to the McKinsey report, the use of these platforms is linked to a $9 \%$ productivity increase and a reduction in recruitment costs of around $7 \%$. If, on the one hand, it seems clear that technology is changing the labor market (Howard 2015), on the other hand, academic research has so far failed to show any tangible interest in the connection between the use of digital platforms and the increase in the number of independent workers. On this last topic in particular, there are no official statistics that outline in any precise manner the extent of this trend (Manyiika et al., 2015). When we discuss the role of digital intermediaries in the world of labor, we should carefully consider the influence that platforms such as LinkedIn, Monster and TaskRabbit have. Thanks to these platforms, millions of people around the world have access to professional openings that they would otherwise not have or even know about. The offer and demand on these sites meet up quickly and easily, allowing a huge reduction in the amount of time a worker remains idle, workers who have a greater chance of moving from one position to another without being unemployed for too long.

The McKinsey report distinguishes three categories of digital platforms:

1) Platforms that offer the opportunity of finding work and workers; sites such as LinkedIn, Monster, Vault, Indeed, Careerbuilder, Xing and Glassdor fall into this category,

2) Platforms that create a connection between those who are looking for a particular service, and those in the position to offer that service. In this category we find sites such as Uber, TaskRabbit, Angie's List, Upwork and Amazon Home Service;

3) Platforms that discover and manage talent. Examples of these sites are Good.co, Payscale and ReviewSnap.

One of the main characteristics of these sites is that workers can freely choose the type of employment they are looking for, as well as the companies for which they would like to work. In the same way, an employer can set out the minimum requirements candidates should have for any particular position. On a larger scale, the impact digital platforms have can be perceived with particular regards to an increase in the flexibility of the labor market. This flexibility has very evident consequences with regards to productivity, true salaries and levels of unemployment (Davis \& Haltiwanger, 2014). The theme of flexibility is one that has great importance in economic literature (Shimer, 1998, 2001; Molloy et al., 2016; Flek et al., 2015) where we can find evidence of a strong connection between a low level of flexibility of the labor market and the deterioration of the economical performance of that particular country. If digital platforms, therefore, produce greater flexibility and, as a result, improvements in unemployment levels, real salaries and productivity, we can deduce that the expansion of this new instrument for recruitment will, in the long term, provide considerable economical advantages. Researchers have yet to provide any solid contributions to this topic, and they have not yet concentrated on the direct link between the expansion of these digital platforms and the economical performance at an industrial or national 
level. For the time being, we can focus on the reports described in fig.1, while future attention should be paid to the factors outlined in fig.2.

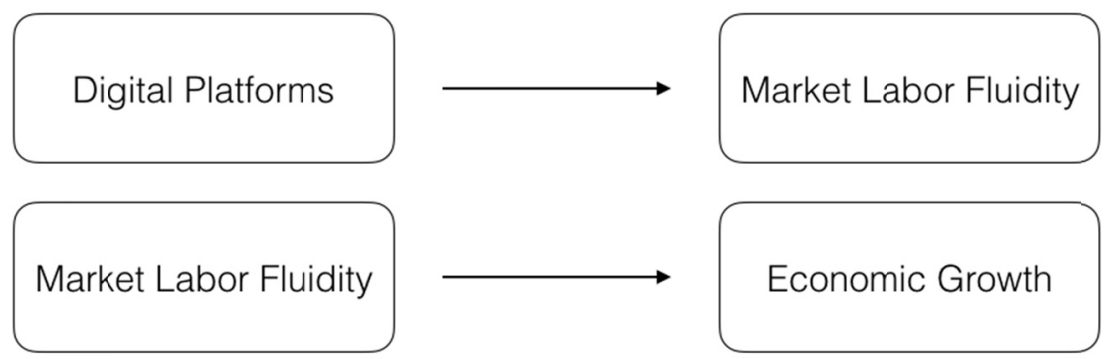

Figure 1. There are still no specific contributions regarding the link between digital platforms and the growth of economical indexes

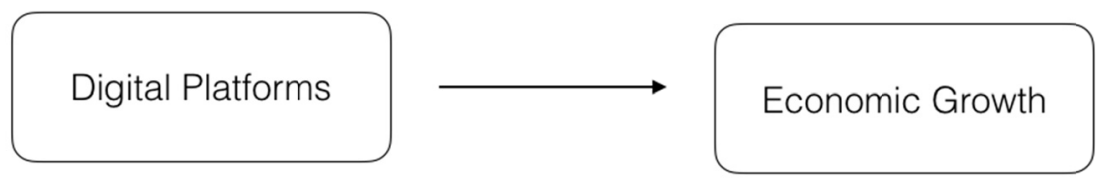

Figure 2. It would be interesting to determine if and in which way the use of digital platforms helps to improve economical indexes

Fig. 2, in some ways, summarises the reasons why it is important to discuss digital platforms and the impact they have on the labor market. This market is, in fact, going through a period of profound change where online digital platforms will play an increasingly important role. The use of digital social instruments is currently booming as never before, especially if one considers that around $29 \%$ of the world population has at least one active social account (We Are Social, 2016). If, then, we turn our attention from the macroeconomic context to that of organizational aspect, we can not fail to consider the impact these social platforms are having on human resource management mechanisms, while many researchers are already outlining the extent of this current transformation (Poba-Nzaou et al., 2016). Digital platforms are revolutionizing the way in which organizations communicate with the outside world, making their influence felt in numerous aspects of the life of an organization, such as marketing, operations and human resources (Aral et al., 2013).

Due to the fact that these instruments are relatively new, the various engagement mechanisms by which employers come into contact with workers has yet to be explored in any detail. One of the changes is the creation and sharing of knowledge which, more than ever before, can speed up innovation processes thanks to the way it is created and shared. Over the past few years, specific studies have been carried out on techniques human resource managers can use to deal with the new challenges presented by technology. In this field of research, there is a range of contributions by the Strategic HRM itself (Lengnick-Hall et al. 2009; Marler \& Parry, 2016) and of the so-called e-HRM (Strohmeier, 2007; Ruël \& van der Kaap, 2012). According to Marler and Fisher (2013) the two fields of research are closely connected, even if we can not describe it as a random strategic approach between human resources and e-HRM. The appearance of these two branches of research is relatively new, and in both cases the emphasis is placed on the role that human resource management can play within organizations when it comes to implementing changes, thus minimizing personnel management costs. It is a fact that the role of HR has changed since the introduction of Internet, helping the creation of an ever increasingly tight relationship between workers' skills and the business objectives of the company, even if some researchers stress that such relationship is not always achievable (Marler, 2009). The Strategic Human Research Management (SHRM) can be observed from two different angles: the strictly strategic angle, which assesses the impact of HR policies on the basis of the engagement the business has with the outside world (Porter, 1985), and the angle which has closer ties to the Resource-Based View (Penrose, 1959). In the first case, while the impact on the outside world is considered to be a determining factor, good human resource management policies can only be successful to the extent of its alignment to the overall strategies of the business. In the second case, the determining factor is considered to be the ability of the organization to place its intellectual wealth at the centre of its business strategies. If we observe the SHRM from the RBV point of view, we can determine how important the role of human resource is in organizations which endeavor to invest in the creation and development of 
knowledge. Dealing with the impact that digital platforms have on the internal labor organization of businesses is somewhat like revisiting the discussion regarding the relationship between technology and organizations. In a famous article, Orlikowski and Scott (2008), after having reviewed four of the world's leading management journals (The Academy of Management Journal, The Academy of Management Review, Administrative Science Quarterly and Organization Science), came to the conclusion that over $95 \%$ of the articles published between January 1997 and December 2006 failed to take into any form of consideration the role played technology within organizations. In other words, technology appears to be considered as an evanescent factor and with very little importance, despite its presence becoming evermore widespread and essential. After having reviewed 2027 articles, Orlikowski and Scott discovered that precise reference was made to the impact technology is having on organizations in only 100 articles (4.9\% of the total). Some researchers agree in claiming that this form of indifference has intensified over the last 30 years (Zammuto et al., 2007), just at the time when technology has been increasing its presence in organizations. This statistic leaves us somewhat bewildered as it suggests that the academic world has distanced itself from certain subjects, right at the time when it should, on the other hand, be treating them with far greater attention. One possible explanation could lie in the fact that the technological transformation has been so rapid and unpredictable, that the ability to comprehend could not keep up with the speed of progress (Orlikowski \& Scott, 2008). The relationship between technology and organizations inevitably has a large influence on the role of HR, which is why we hear more often about electronic Human Resource Management (e-HRM). This subject deals with the use of electronic instruments as support for human resource management and has been conceptualized in a methodical manner by Strohmeier (2007), in addition to other earlier contributions on this subject (Stanton \& Coovert, 2004). HRM can carry out numerous operations with electronic support, even if, when speaking about digital platforms, we only think essentially of the recruitment phase, so much so that we often speak explicitly about e-Recruitment (Sylva \& Mol, 2009). As we have just seen, digital platforms are having an impact on the labor market and organizations like never before. More specifically, what has changed is the way human resource professionals operate. While there are similarities in the ways various managers use electronic instruments for recruitment and personnel management, there can be differences in individual fields of industry. For example, Gibbs and his colleagues (2015) studied the impact digital platforms are having on HR roles in the hospitality industry. It should be stressed that the platforms especially designed for the labor market are not the only ones to have a more or less direct impact on the business world. Alongside sites like LinkedIn and TaskRabbit, we should also consider the role of social media sites (Facebook, Twitter, Instagram, Snapchat,...) which, while not directly connected to the amalgamation of labor supply and demand, they can, however, influence the way workers are perceived and subsequently recruited by HR managers (Girard et al., 2013). In other words, we should consider digital platforms as being a wide ranging field within which both labor and social platforms are contained. Fig. 3 explains the relationship between the use of digital platforms ("for work" and "social") and the new role played by Human Resource Management, with specific reference to the recruitment phase.

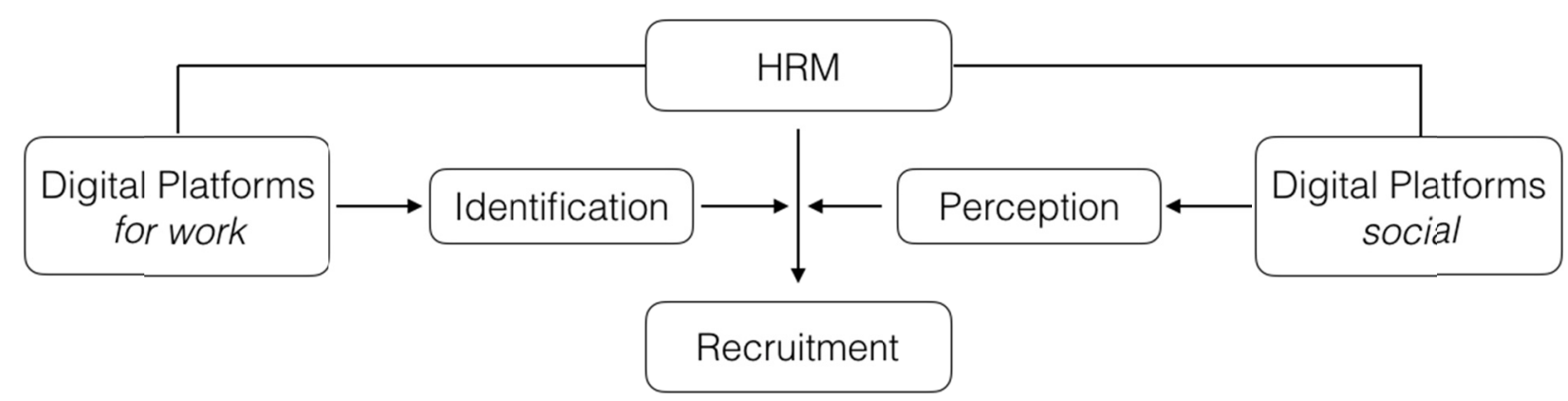

Figure 3. The use of digital platforms by HRM has varying impacts on the recruitment process, depending on the types of platforms used

Not all digital platforms are the same and even those not specifically designed for the labor market can have a bearing on decisions made by HRM when it comes to recruiting new personnel. Without any doubt, platforms such as LinkedIn help to identify those workers whose characteristics are more suitable to those the business is 
looking for. A worker can, in fact, promote the entire range of his or her expertise on these sites, placing emphasis, for example, on any of their particularly strong professional expertise that may attract the attention of HR professionals. We should be aware, however, that identification is not enough for finding employment. HR managers very often look at social media profiles of selected candidates before summoning them for an interview, or immediately after the interview, in order to obtain a more detailed picture of the candidate's "lifestyle". From this point of view, social networks represent a force that influences the perception a manager may have of a particular candidate, as often the attention is not only focused on what the person can do, but also, and sometimes above all, on the values the candidate holds and the messages he or she conveys from their personal digital space. It's no mystery, therefore, that a lot of employers read the social pages of those who offer themselves as candidates for employment, in order to decide whether to employ them or otherwise (Brandenburg, 2008; Brown \& Vaughn, 2011). The impact digital platforms have on HR practices are not only felt in the private sector but it is also starting to be the subject of studies in the public administration sector as well (Bryer \& Zavattaro, 2011; Tufts et al., 2015). If, on the one hand, we can assert that social platforms can influence the perception an organization may have of a particular candidate, on the other hand it is also true that social media can change the perception a worker may have of a certain organization (Melian-Gonzalez \& Bulchand-Gidumal, 2016). Over the past years, numerous websites have been created where opinions and evaluations are expressed by workers regarding a particular organization. This trend is known as worker electronic word of mouth (weWOM) (Van Hoye \& Lievens, 2009). It is important for us to remember the dual nature of this perception, due to the fact that social platforms accentuate, in both a negative and a positive manner, not only the image of a worker, but also that of an employer. It becomes clear, therefore, that if a potential candidate has a negative perception, this can keep him or her away from a particular business, resulting in this business appearing to be unappealing and which therefore potentially misses out on skilled candidates. The function of HR in implementing recruitment strategies, is that of understanding how to use its social platforms in the most suitable way. This game of recruitment, in general, and of perception in particular, runs in both directions, from the organization to the individual and from the individual to the business. If "for work" digital platforms allow individuals to identify a work opportunity, and organizations to spot a potential candidate, in the same way social platforms can act on reciprocal perception between individuals and organisations. In a way, it is as if fig. 3 were re-elaborated from the point of view of job seekers. The result is shown here in fig. 4.

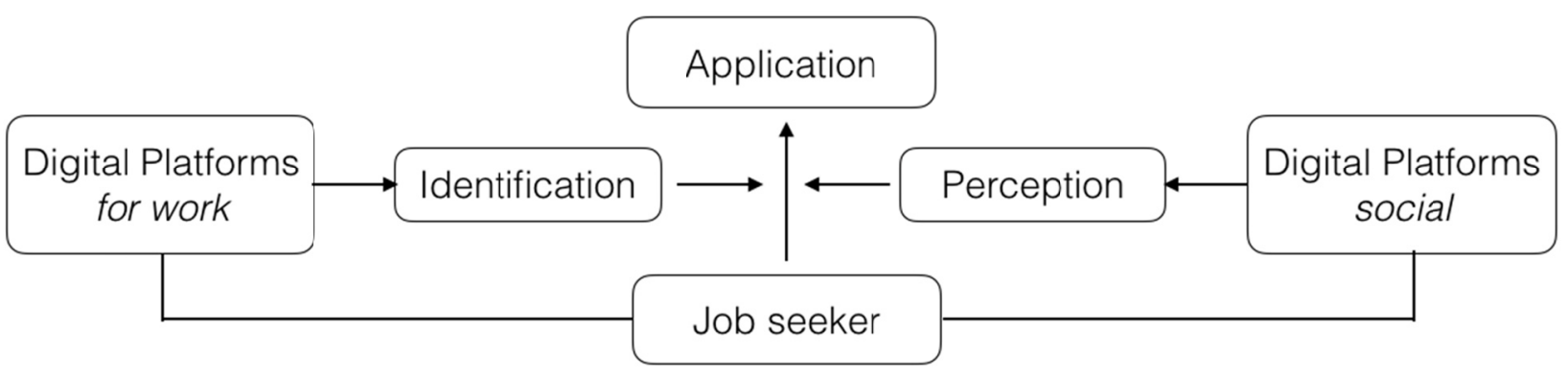

Figure 4. The use of digital platforms by job seekers has varying impacts on application processes, depending on the type of digital platform used

As competition between organisations increases for acquiring the best talents, those who are looking for employment certainly have better instruments for accessing information regarding their career. Today, candidates have a better chance of negotiating than before, as information regarding the subject of their negotiations, such as the salaries of those who have a similar occupation, is more readily available (Phillips-Wren et al., 2016). Managerial literature has, more recently, emphasized the role that these social platforms play in recruitment processes. What, we believe, isn't mentioned, is the fact that not all of these platforms are the same and, for this reason, we should distinguish between platforms specifically created for labor and social platforms. Each of the two types of platform influences decisions made by HR managers and by candidates on two different fronts, identification and perception.

When we talk about identification, we are referring to: 
- The way in which an organization identifies potential candidates, on the basis of information pertaining to their professional characteristics;

- The way in which candidates identify an organization for which they would potentially like to work, on the basis of information pertaining to the business activities of the company.

When, however, we talk about perception, we are referring to:

- The way in which an organization perceives the candidate, on the basis of information pertaining to their extra-professional characteristics

- The way in which the individual perceives the organization, on the basis of information pertaining to characteristics not entirely related to its business activities.

Figure 5 shows a summary of the contents of figure 3 and figure 4 .

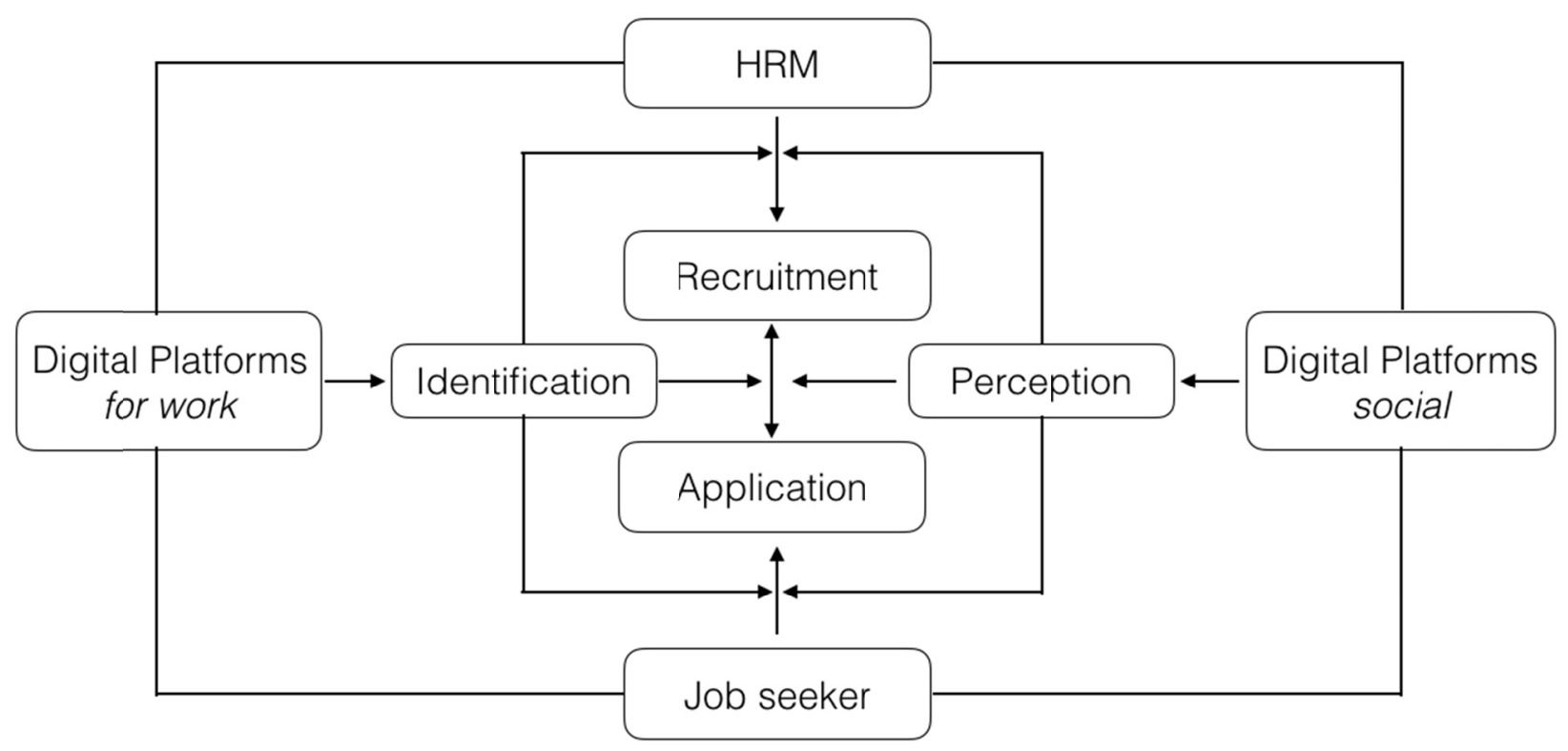

Figure 5. Digital platforms have an impact on the identification and perception processes, from both the HRM's and Job Seeker's point of view

Digital platforms influence the way in which the HRM identifies and perceives a potential candidate. If both processes are successful, it becomes very likely that the recruitment phase will be reached. In the same way, these same platforms influence the way in which the job seeker identifies and perceives a particular business. Even in this case, if both processes have a successful outcome, the chances are that the candidate will apply for a position in that particular business. It is apparent that, on the whole, digital platforms not only influence perception and identification by both the HRM and the job seeker, but that they also have a bearing on the engagement between application and recruitment. It is also clear that without a specific application, recruitment would become impossible and that, in the same way, without the wish to reach the recruitment phase, the application would not generate the desired effect. The table shown in fig. 5 is particularly representative of the fields in which both business and individuals with a strong digital vocation operate.

\section{The impact Co-working Spaces have on Motivational Management Processes}

Over the last few years a large scale phenomenon has been taking place, which is the sharing of work spaces between employees and independent workers. Co-working is somewhat more than just simply sharing an office. It is an opportunity for social interaction, the sharing of knowledge, the continuous engagement between workers, who may even work in fields that are very far apart. In 2015, it was calculated that globally there were around 7800 co-working spaces with a growth rate of $83 \%$ between 2012 and 2013 and 36\% between 2014 and 2015 (Foertsch, 2013, 2015). According to some, Brad Neuberg was one of the first to use the term "co-working" when, in 2005, he founded the Hat Factory in San Francisco (Jones et al., 2009). The idea at the base of 
Neuberg's initiative derived from a very simple observation. Until that moment, a worker could choose, when choice was effectively available, between working in an office and working from home. The co-working space, from this point of view, was a form of compromise. A way of disconnecting oneself from the stress of a large office to the solitude of a home. For many, co-working today continues to be just this. In other words, an opportunity for relational engagement outside the boundaries of a traditional office. It is from this relational engagement that significant implications arise with regards to creation and exchange of knowledge. Over the past few years, some researchers have concentrated their studies on the types of relationships that are created by the closeness between workers within a co-working space, and the flow of knowledge that is thereby generated (Parrino, 2015). The subject becomes particularly interesting if we consider the types of individuals that can be found within a shared space. Traditionally, co-working was a method used by independent professionals who worked as freelancers or who autonomously ran a business enterprise. Gradually, a new reality emerged which saw other individuals inside the confines of these spaces. On this subject, Parrino (2015) outlines the heterogeneity of the new co-working spaces, identifying three large groups of individuals who work inside these spaces:

1) Freelancers;

2) Micro-businesses;

3) Employees or autonomous workers who work for organisations whose head offices are outside the co-working space.

We should not be surprised, therefore, if an increasing number of organisations decide to set up their head offices in spaces like this. The human resource managers in these organisations inevitably find themselves having to face new dynamics of knowledge management. In these cases, managing knowledge is no longer a closed process, a process which is born within the more or less clear confines of the business, but it becomes an open process in which the flow of knowledge originates from its own workers as well as workers from other organisations. This is the result of proximity between workers, which characterizes a large number of young companies that decide to operate from within a shared structure, and where the presence of another business literally becomes physical.

Inside these co-working spaces, companies not only let their own employees work but, in the same space, they can also attempt to hire new freelancers. Genuine alliances based on the dynamics of co-working can be born from methods of collaboration of this kind. These alliances can grow in the spaces where these individuals physically work, or they can extend themselves beyond the material confines of the work space, leading to virtual co-working (Andrade et al., 2013). The choice of co-working can be the source of numerous benefits. Among these, many underline the clear benefit of being able to increase the general levels of work productivity (Ross \& Ressia, 2015), or that of being able to more easily gain access to a wide range of advanced skills, without forgetting the improved results in terms of job satisfaction and work/life balance (Bosua et al., 2013).

If an organization is looking for so-called staff on demand, inside co-working spaces appears to be the ideal place for engaging with freelance workers. As Kubàtovà (2014) does in fact remind us, freelancers are like small business people who offer, from within their co-working spaces, their intellectual wealth to all those organisations that require particular skills. This trend is definitely on the increase while very few studies on the matter have researched in full the implications that this phenomena creates. Rus and Orel (2015) tried to discover the reasons that explain the growth of these shared spaces. In their view, the "creative class" plays an important role, a class which thrives on sharing knowledge and information. This category of worker finds co-working the ideal place for satisfying this need for engagement. This type of explanation should be placed into the much wider context of the profound change that the labor market has undergone over the last decade. Pfeffer and Baron (1988), for example, realised twenty years ago that turning to outsourcing had strongly shaped the way in which organisations related to their workers, underlining the emergence of an ever increasing use of outsourcing in labor relations. The approach adopted by organisations within this field of reference, is a sign of changing times. In this current economic context, we have moved from the age of competition to the age of cooperation (Snow, 2015) and co-working, in this perspective, could well be considered as a means for simplifying, which is the cause and effect of the changing scene in which organisations operate. Bouncken e Reuschl (2016), in one of their recent articles, explicitly expressed their desire to introduce the matter of co-working spaces into managerial science. In their opinion, the way in which this topic has been treated up until now, has not been of a systematic nature. One of the points raised by the authors, and which they were keen to underline, was the fact that all we know about co-working is the fact that it is of a semi-scientific nature, as it derives from sources that, in most cases, have no form of influence in the economic and managerial fields. The study carried out by 
Spreitzer and colleagues (2015) is an exception to this state of affairs, a study where the authors tried to comprehend why workers who operate inside co-working spaces appear to perform better than their colleagues who work from traditional offices. After having interviewed numerous founders of co-working spaces, the study outlined three fundamental factors, which can help to explain the connection between co-working and growth in individual performance:

1) Workers who operate in co-working environments feel that their work has greater purpose;

2) There is a feeling that there is greater control of their work in co-working spaces;

3) "Co-workers" feel as if they are part of a community.

Seeing as the benefits that derive from this form of working environment are numerous and apparent, a lot of businesses prefer resorting to using co-working spaces for certain activities, even if they already have their own office space. In the same way, there are a lot of employees who, instead of going to work in their company's offices, prefer to work at a desk in a co-working space.

As we have already seen with digital platforms, even here there are significant implications for HRM that should be underlined. In this particular case, the process that mostly comes into play is not that of recruitment but rather that of operational management of human resources, in other words, those decisions that can affect the way in which workers perceive their job and their role within the organization. To explain it in other words, the strategic use of co-working spaces can have a direct impact on personnel motivation and, indirectly, on performance. Let's consider for a moment the question just posed regarding the importance of a person's work. As Spreitzer and colleagues (2015) affirm, those who work in co-working spaces treat their work with far greater importance. Being surrounded by people who carry out professions different to their own, for example, can help to highlight the unique qualities of a professional who, in an environment such as this, has no reason to have a competitive attitude, as he or she will probably never come into contact with other people working on a similar project. Working without this kind of pressure can help to reduce stress levels, and a worker who suffers from less stress certainly has greater motivation to carry out his daily activities. In a co-working space, you are likely to come into contact with people who need advice or who, quite simply, are looking for an exchange of ideas. In this case, workers feel useful, not only to themselves, but to the people around them, and this can only have a positive impact on their self-esteem. It goes without saying that this further example illustrates an obvious source of motivation. At this stage, we can assert that co-working has beneficial effects in motivational terms, and this can only be an important factor to consider for those who work with human resource management. Co-working can, therefore, be used as a general motivational incentive in the sense that having the opportunity to work in a shared space, in which the full independence of a worker can emerge, represents a strong incentive for everyone. In some cases, for example, the mere fact of holding a meeting in an "on demand meeting room", located inside a co-working space, can break that sense of restriction felt by those you constantly work within the walls of the business they work for. Fig. 6 shows us on which fronts future research should concentrate on in order to examine the aspects of co-working practices relevant to HRM which can subsequently strengthen motivation within a company. From the small amount of literature available to us on this topic, we can deduce that there are three general areas where co-working has an effect:

1) work identity

2) sense of community

3) job control

The strengthening of these factors acts on the motivational aspect of the worker. As a result, HRM can, within the boundaries allowed by the use of co-working, more easily manage motivational aspects in the sense that it can be strengthened by acting upon one single source, rather than on three different sources. 


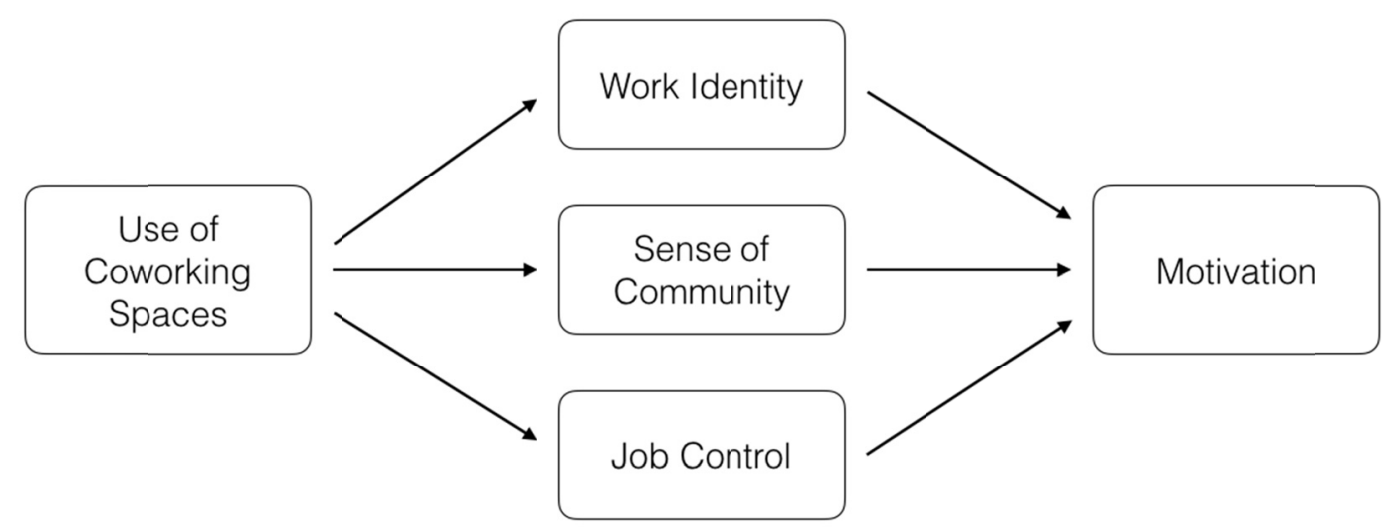

Figure 6. Working inside Co-working spaces can improve the worker's conditions on at least three fronts. This type of improvement has a positive effect on motivation

Some businesses set up their head offices inside co-working spaces or leave their workers free to use them (Waber et al., 2014; Spreitzer et al., 2015). In both cases, what is significant is the effect this decision has on the motivational aspects of workers.

With regards to the link between identity and motivation, there are various studies that explain how the first factor can lead to an increase in the second. According to widely published theories, work identity has a positive effect on engagement which, in turn, inevitably leads to an increase in motivation (May et al., 2004; Popova-Nowak, 2010). For this reason we can assert that if the co-working space acts on identity which, in turn, has an impact on motivation, there must therefore be a connection between co-working and motivation, albeit an indirect one. With reference to this second connection, it should be said that the generic term sense of community can take on numerous meanings according to the field in which it is used (Pretty et al., 2006). Some experts have recently spoken about the need to reconsider businesses as if they were communities (Mintzberg, 2009). Nevertheless, the sense of belonging to a community, when we talk about co-working, does not develop within the boundaries of the company, but in spaces where one is surrounded by workers coming from different fields and with diverse backgrounds. In this case, the method used for improving motivation is different to that normally used. Usually, for example, HRM must deal with activating processes aimed at increasing commitment, as feeling part of a company in which you work helps to increase motivation (Meyer \& Allen, 1991). In the case of co-working, however, it is always the sense of belonging that triggers motivation, but with the important difference that this is not a sense of belonging to the company you work for, but to your community of co-workers. In one sense, the place in which the sense of belonging develops (sense of community) and the place in which the effect of this sense of belonging (motivation) produces its results, do not coincide. Finally, we have outlined a further connection between co-working, job control and motivation. The literature that is emerging about connections between co-working spaces and the psychological impact on workers, tells us that working in an environment which is accessible 24 hours a day, helps to provide greater control over a person's work (Spreitzer et al., 2015), as they are free to decide when and how long to work and to manage breaks and workload sharing in full autonomy, and without, therefore, having to endure the stress of strict control over one's work. Managerial literature, on the other hand, often talks about empirical evidence showing proof that control over a person's work helps that person to gain clear benefits in terms of psychophysical health (Minchie et al., 2004; Minchie \& West, 2004). If people who control their own work are more greatly motivated and if, at the same time, co-working helps to carry out this form of control, it therefore becomes evident that a connection similar to that outlined in fig. 6 can be found. We would need to combine the traditional literature, looking into Human Resource Management and Organisations, with the more recent studies regarding co-working, so as we can create a new framework, highlighting how new human resource management processes can influence psychological and managerial mechanisms which have widely been discussed in the past

\section{Conclusions}

The labor market is ever increasingly characterized by the presence of independent workers who, in a very generic way, are known as freelancers. These workers make up a large proportion of the total workforce currently present in the current economic context and, for this reason, in order to comprehend their role, we should interpret the concept of freelance workers in the correct way. In this article, we have tried to follow the 
differentiation offered by "Freelancing in America", thanks to which we can deduce that each and every freelancer plays a different role in the so-called Gig Economy. Organisations, on the other hand, are nowadays having to manage Human Resources which are becoming more and more varied. If, in fact, on the one hand the presence of contractors in business is increasing, on the other hand, the role played by full-time workers is fundamental. As a result, HR mangers are more increasingly finding themselves having to deal with an integrated personnel management system, in other words, a system which has the ability to enhance the contributions offered by both categories of workers. After having reviewed various studies taken from managerial and economical literature on this topic, we found that there are at least two factors that are becoming fundamental for modern organizations, as they provide support for personnel management policies, with regards to both recruitment and motivation. These factors are: digital platforms and co-working spaces. With regards to digital platforms, we have attempted to focus on the role they play in the recruitment process, highlighting the fact that not all platforms are the same. Despite the fact that a large number of researchers do not place emphasis on the difference between these platforms, it has to be said that they have varying methods of use and purposes. If, in fact, "for work" platforms such as LinkedIn and TaskRabbit assist HRM in identifying workers, "social" platforms such as Facebook and Twitter help to catch aspects of potential candidates (values, beliefs, lifestyles) that would otherwise remain in the shadows, and while these aspects are not directly connected to the candidate's professional skills, organisations consider them as being very important. With regards to co-working spaces, on the other hand, the small amount of literature that is currently available to us for consultation tends to assert that these spaces favour the growth of at least three psychological aspects of workers: work identity, sense of community and job control. A vast amount of literature is available on these three factors which tell us without a shadow of doubt that each of them lead to an improvement in motivation. When we combine, therefore, the emerging literature on co-working with traditional literature focusing on motivation, we can conclude that workers who operate within a shared space, experience a marked improvement in their performance.

\section{Implications for HRM}

The current context of the so-called "freelancer economy" sees organisations taking on new challenges, which are mainly connected to personnel management. As Human Resources change, we need to rethink and redesign those approaches which were used in the past for resolving worker management problems. Some of the most important problems are those connected to recruitment and motivation. An appropriate use of digital platforms and co-working spaces can lead to a strategic use of Human Resources, as talented people not only have to be enticed and identified in the correct way but, once they are hired, they have to be motivated in the best possible way in order not to risk losing the precious contribution that can be gained from their individual performances. Nowadays, these digital platforms represent one of the main gateways to talent, and talent, in an economy which is ever increasingly based on knowledge, is the principle source of success and differentiation. In the same way, co-working spaces are rapidly booming, a factor which leads us to ask precise questions as to the reason behind this trend. In all likelihood, workers - freelance or otherwise - feel an ever increasing need for autonomy and self-determination when it comes to managing their daily activities, and co-working spaces successfully satisfy these expectations. Once again, then, the challenge facing HRM is that of adapting itself to management procedures and to the policies of our changing times, because never before has this change been so rapid.

Fig. 7 sums up the theoretical approach described in this article.

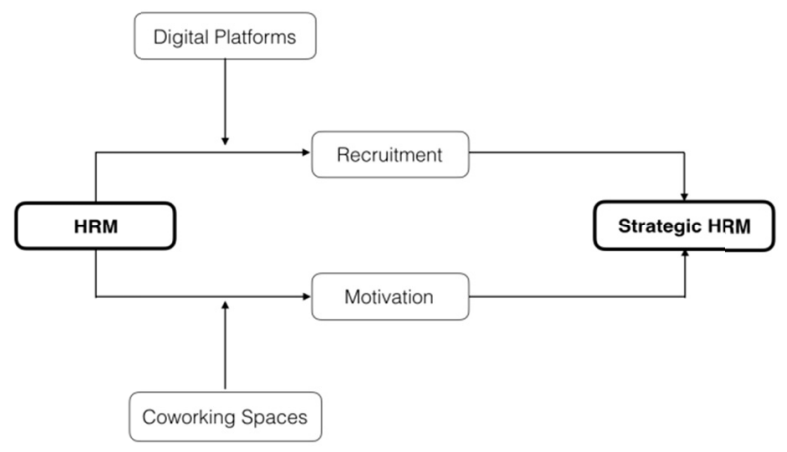

Figure 7. The use of digital platforms and resorting to co-working can assist HRM management in improving two important personnel management processes, such as those of motivation and recruitment. In this way, strategic human resource management is simplified 
By using precise instruments or solutions, such as digital platforms and co-working, Human Resource management can become strategically important in at least two ways. From the first point of view and with regards to recruitment, digital platforms supply a more detailed picture of the candidate that is about to be hired. In this way, the human resource that is about to be placed into the heart of the business, can be evaluated in greater detail. From the second point of view and with regards to motivation, co-working improves the psychological state of workers in a number of ways and this can only lead to an increase in individual performances, indirectly improving the all-round performance of the organization.

\section{References}

Andrade, J., Ares, J., Suarez, S., \& Giret, A. (2013). Implementation challenges for supporting coworking virtual enterprises. Proceedings of the 10th International conference on e-Business Engineering (ICEBE), Conventry, UK, (11-13 September), 9-16.

Aral S., Dellarocas, C., \& Godes, D. (2013). Introduction to the special issue. Social media and business transformation: a framework for research. Information Systems Research, 24(1), 3-13. https://doi.org/10.1287/isre.1120.0470

Barley, S. R., \& Kunda, G. (2006). Contracting: a new form of professional practice. The Academy of Management Perspectives, 20(1), 45-66. https://doi.org/10.5465/AMP.2006.19873409

Bosua R., Gloet, M., Kurnia S., Mendoza, A., \& Yong, J. (2013). Telework, productivity and wellbeing: an Australian perspective. Telecommunications Journal of Australia, 63(1), 11.1-11.12.

Bouncken, R. B., \& Reuschl, A. J. (2016). Coworking-spaces: how a phenomenon of the sharing economy builds a novel trend for the workplace and for entrepreneurship. Review of Managerial Science. https://doi.org/10.1007/s11846-016-0215-y

Brandenburg, C. (2008). The newest way to screen job applicants: a social networker's nightmare. Federal Communications Law Journal, 60(3), 597-626.

Brown, V., \& Vaughn, E. (2011). The writing on the (Facebook) wall: the use of social networking sites in hiring decisions. Journal of Business and Psychology, 26(2), 291-225. https://doi.org/10.1007/s10869-011-9221-x

Bryer, T., \& Zavattaro, S. (2011). Social media and public administration: theoretical dimension and introduction to the symposium. Administrative Theory \& Praxis, 33(3), 325-340. https://doi.org/10.2753/ATP1084-1806330301

Bureau of Labor Statistics. (2015). Freelancers in the U.S. Workforce, Monthly Labor Review, October. https://doi.org/10.21916/mlr.2015.37

Burke, A., \& Cowling, M. (2015). The use and value of freelancers: the perspective of managers. International Review of Entrepreneurship, 13(1), 7-20.

CIETT (International Confederation of Private Employment Agencies). (2010). The Agency Work Industry Around the World. CIETT, Brussels.

Davis, S. J., \& Haltiwanger, J. (2014). Labor market fluidity and economic performance. National Bureau of Economic Research. Working Paper No. 20479.

Dell'Anno, R. (2016). Analyzing the determinants of the shadow economy with a "separate approach". An application of the relationship between inequality and the shadow economy. World Development, 84 , 342-356. https://doi.org/10.1016/j.worlddev.2015.08.026

De Cuyper, N., \& De Witte, H. (2008). Volition and reasons for accepting temporary employment: associations with attitudes, well-being and behavioural intentions. European Journal of Work and Organizational Psychology, 17(3), 363-387. http://dx.doi.org.proxy.lib.utk.edu:90/10.1080/13594320701810373

Flek, V., Hàla, M., \& Mysikovà, M. (2015). Labour market response to economic crisis in Central Europe: is there room for common policy approach? Economics and Sociology, 8(2), 15-27. https://doi.org/10.14254/2071-789X.2015/8-2/2

Foertsch, C. (2013). 4.5 New coworking spaces per work day. Deskmag, March 4. Retrieved from http://deskmag.com/en/2500-coworking-spaces-4-5-per-day-741

Foertsch, C. (2015). First results of the new global coworking survey. Deskmag, November 20. Retrieved from $\mathrm{http}$ ://deskmag.com/en/first-results-of-the-new-global-coworking-survey-2015-16

Gibbs, C., MacDonald, F., \& MacKay, K. (2015). Social media usage in hotel human resources recruitment, 
hiring and communication. International Journal of Contemporary Hospitality Management, 27(2), 170-184. https://doi.org/10.1108/IJCHM-05-2013-0194

Girard, A., Fallery, B., \& Rodhain, F. (2013). Integration of social media in recruitment: A Delphi study. Social media in Human Resource Management, 97-120.

Goodman, M. (2010). Freelancing? Think like a Business Owner. Entrepreneur, January 12. Retrieved from https://www.entrepreneur.com/article/204576

Holland, P., Cooper, B. K., \& Hecker, R. (2016). Use of social media at work: A new form of employee voice? International Journal of Human Resource Management, 27(21), 2621-2634. http://dx.doi.org/10.1080/09585192.2016.1227867

Howard, A. (2015). How digital platforms like LinkedIn, Uber and Task Rabbit are changing the on-demand economy. The Huffington Post (US edition). Retrieved from http://www.huffingtonpost.com/entry/online-talent-platforms_us_55a03545e4b0b8145f72ccf6

Jones, D., Sundsted, T., \& Bacigalupo, T. (2009). I'm outta here! How Coworking is making the office obsolete. Not an MBA press, Austin, TX.

Kitching, J., \& Smallbone, D. (2012). Are freelancers a neglected form of small business? Journal of Small Business and Enterprise Development, 19(1), 74-91. https://doi.org/10.1108/14626001211196415

Kubàtovà, J. (2014). The cause and impact of the development of co-working in the current knowledge economy. Proceedings of the European Conference on Knowledge Management, 2, 571-577.

Lemmon, G., Wilson, M. S., Posig, M., \& Glibkowski, B. C. (2016). Psychological Contract Development, distributive justice, and performance of independent Contractors: the role of negotiation behaviors and the fulfillment of resources. Journal of Leadership \& Organizational Studies, 23(4), 424-439. https://doi.org/10.1177/1548051816645745

Lengnick-Hall, M. L., Lengnick-Hall, C. A., Andrade, L. S., \& Drake, B. (2009). Strategic human resource management: the evolution of the field. Human Resource Management Review, 19(2), 64-85. https://doi.org/10.1016/j.hrmr.2009.01.002

Manyika, J., Lund, S., Bughin, J., Robinson, K., Mischke, J., \& Mahajan, D. (2016) Independent work: choice, necessity, and the gig economy. McKinsey Global Institute Report, October.

Manyika, J., Lund, S., Robinson, K., Valentino, J., \& Dobbs, R. (2015). Connecting talent with opportunity in the digital age. McKinsey Global Institute Report, June.

Marler, J. H. (2009). Making human resources strategic by going to the Net: reality or myth? The International Journal of Human Resource Management, 20(3), 515-527. http://dx.doi.org/10.1080/09585190802707276

Marler, J. H., \& Fisher, S. L. (2013). An evidence-based review of e-HRM and strategic human resource management. Human Resource Management Review, 23(1), 18-36. https://doi.org/10.1016/j.hrmr.2012.06.002

Marler, J. H., \& Parry, E. (2016). Human resource management, strategic involvement and e-HRM technology. The International Journal of Human Resource Management, 27(19), 2233-2253. http://dx.doi.org/10.1080/09585192.2015.1091980

May, D. R., Gilson, R. L., \& Harter, L. M. (2004). The psychological conditions of meaningfulness, safety, and availability and the engagement of human spirit at work. Journal of Occupational and Organizational Psychology, 77(1), 11-37. https://doi.org/10.1348/096317904322915892

Melian-Gonzalez, S., \& Bulchand-Gidumal, J. (2016). Worker word of mouth on the Internet: influence on human resource image, job seekers and employees. International Journal of Manpower, 37(4), 709-723. https://doi.org/10.1108/IJM-09-2014-0188

Meriküll, J., \& Staehr, K. (2010). Unreported employment and envelope wages in mid-transitions: Comparing developments and causes in the Baltic countries. Comparative Economic Studies, 52(4), 637-670. https://doi.org/10.1057/ces.2010.17

Meyer, J. P., \& Allen, N. J. (1991). A three-component conceptualization of organizational commitment. Human Resource Management Review, 1(1), 61-89. https://doi.org/10.1016/1053-4822(91)90011-Z

Miller, J. G., \& Miller, M. (2012). The rise of Supertemp. Harvard Business Review, 90(5), 50-62.

Minchie, S., Wren, B., \& Williams, S. (2004). Reducing absenteism in hospital cleaning staff: pilot of a 
theory-based intervention. Occupational and Environmnetal Medicine, 61(4), 345-349. http://dx.doi.org/10.1136/oem.2003.009639

Minchie, S., \& West, M. A. (2004). Managing people and performance: an evidence based framework applied to health service organizations. International Journal of Management Reviews, 56(2), 91-111. https://doi.org/10.1111/j.1460-8545.2004.00098.x

Mintzberg, H. (2009). Rebuilding companies as communities. Harvard Business Review, 87(7-8), 140-143.

Molloy, R., Trezzi, R., Smith, C. L., \& Wozniak, A. (2016). Understanding declining fluidity in the U.S. labor market. Brookings Papers on Economic Activity, Issue Spring, 183-259.

Oliver, S. (1993). Moonlighter's delight. Forbes, 151(13), 198, June 21.

Orlikowski, W. J., \& Scott, S. V. (2008). Sociomateriality: challenging the separation of technology, work and organization. The Academy of Management Annals, 2(1), 433-474. https://doi.org/10.1080/19416520802211644

Parrino, L. (2015). Coworking: assessing the role of proximity in knowledge exchange. Knowledge Management Research \& Practice, 13(3), 261-271. https://doi.org/10.1057/kmrp.2013.47

Penrose, E.T. (1959). The Theory of the Growth of the Firm, New York: John Wiley.

Pfeffer J. \& Baron J.N. (1988). Taking the workers back out: recent trends in the structuring of employement. In B.M. Staw and L.L. Cummings (eds.). Research in Organizational Behavior, 10, 257-303.

Phillips-Wren, G., Doran, R., \& Merrill, K. (2016). Creating a value proposition with a social media strategy for talent acquisition. Journal of Decision Systems, 25(sup.1), 450-462. http://dx.doi.org/10.1080/12460125.2016.1187398

Poba-Nzaou, P., Lemieux, N., Beaupré, D., \& Uwizeyemungu, S. (2016). Critical challenges associated with the adoption of social media: a Delphi of a panel of Canadian human resources managers. Journal of Business Research, 69(10), 4011-4019. https://doi.org/10.1016/j.jbusres.2016.06.006

Porter, M. E. (1985). Competitive Advantage. New York: The Free Press.

Popova-Nowak, I. V. (2010). Work identity and work engagement. University Forum for Human Resource Development, International conference on Human Resource Development Research and Practice across Europe.

Pretty, G., Bishop, B., Fisher, A., \& Sonn, C. (2006). Psychological sense of community and its relevance to well-being and everyday life in Australia. Position paper of the Australian Psychological Society.

Reilly, T. H. (2015). Employees vs Independent contractors status: A critical decision for California employers. Employee Relations Law Journal, 41(1), 47-54.

Ross, P., \& Ressia, S. (2015). Neither office nor home: coworking as an emerging workplace choice. Employement Relations Record, 15(1), 42-57.

Ruël, H. J. M., \& Kaap van der, H. G. (2012). E-HRM usage and value creation. Does a facilitating context matter? German Journal of Research in Human Resource Management, 26(3), 260-281. https://doi.org/10.1688/1862-0000_ZfP_2012_03_Ruel

Rus, A., \& Orel, M. (2015). Coworking: A community of work. Teorija in Praska, 52, 6.

Sayah, S. (2013). Managing work-life boundaries with information and communication technologies: the case of independent contractors. New Technology, Work and Employment, 28(3), 179-196. https://doi.org/10.1111/ntwe.12016

Schneider, F., \& Enste, D. H. (2000). Shadow economies: size, causes and consequences. Journal of Economic Literature, 38(1), 77-114. https://doi.org/10.1257/jel.38.1.77

Schrader, B. (2015). Here's Why the Freelancer Economy Is On the Rise. Fast Company Magazine. Retrieved from https://www.fastcompany.com/3049532/the-future-of-work/heres-why-the-freelancer-economy-is-on-the-ri se

Shimer, R. (1998). Why is the U.S. unemployment rate so much lower? In NBER Macroeconomics Annual, 13, 11-61. Cambridge, MA: MIT Press.

Shimer, R. (2001). The impact of young workers on the aggregate labor market. Quarterly Journal of Economics, 
116(3), 969-1007. https://doi.org/10.3386/w7306

Snow, C. C. (2015). Organizing in the age of competition, cooperation, and collaboration. Journal of Leadership \& Organizational Studies, 22(4), 433-442. https://doi.org/10.1177/1548051815585852

Sotrey, J., Salaman, G., \& Platman, K. (2005). Living with enterprise in an enterprise economy: Freelance and contract workers in the media. Human Relations, 58(8), 1033-1054. https://doi.org/10.1177/0018726705058502

Spreitzer, G., Bacevice, P., \& Garrett, L. (2015). Why people thrive in coworking spaces. Harvard Business Review, September issue, 28-30.

Stanton, J. M., \& Coovert, M. D. (2004). Turbulent waters: The intersection of information technology and human resources. Human Resource Management, 43(2), 121-125. https://doi.org/10.1002/hrm.20010

Strohmeier, S. (2007). Research in e-HRM: review and implications. Human Resource Management Review, 17(1), 19-37. https://doi.org/10.1016/j.hrmr.2006.11.002

Sylva, H., \& Mol, S. T. (2009). E-recruitment: a study into applicant perceptions of an online application system. International Journal of Selection and Assessment, 17(3), 311-323. https://doi.org/10.1111/j.1468-2389.2009.00473.x

Torka, N. (2004). Atypical employment relationships and commitment: wishful thinking or HR challenge? Management Review, 15(3), 324-343.

Tufts, S. H., Jacobson, W. S., \& Stevens, M. S. (2015). Status update: social media and local government human resource practices. Review of Public Personnel Administration, 35(2), 193-207. https://doi.org/10.1177/0734371X14558066

Van Hoye, G., \& Lievens, F. (2009). Tapping the grapevine: a closer look a word-of-mouth as a recruitment source. Journal of Applied Psychology, 94(2), 341-352. https://doi.org/10.1037/a0014066

Waber, B., Magnolfi, J., \& Lindsay, G. (2014). Workspaces that move people. Harvard Business Review, October issue.

We Are Social. (2015). Digital, social and mobile in 2015. Retrieved November 8, 2016, from $\mathrm{http} / / /$ wearesocial.com/uk/special-reports/digital-social-mobile-worldwide-2015

Webster, J. (2016). Microworkers of the Gig Economy: separate and precarious. New Labor Forum, 25(3), 56-64. https://doi.org/10.1177/1095796016661511

Zammuto, R. F., Griffith, T. L., Majchrzak, A., Dougherty, D. J., \& Faraj, S. (2007). Information technology and the changing fabric of organization. Organization Science, 18(5), 749-762. https://doi.org/10.1287/orsc.1070.0307

Zumbrun, J. (2016). The entire Online Gig Economy Might Be Mostly Uber. The Wall Street Journal. Retrieved from http://blogs.wsj.com/economics/2016/03/28/the-entire-online-gig-economy-might-be-mostly-uber/

\section{Note}

Note 1. Retrieved from https://www.upwork.com/i/freelancing-in-america/2016/

\section{Copyrights}

Copyright for this article is retained by the author(s), with first publication rights granted to the journal.

This is an open-access article distributed under the terms and conditions of the Creative Commons Attribution license (http://creativecommons.org/licenses/by/4.0/). 